\title{
MRI-guided radiotherapy: Opening our eyes to the future
}

\author{
Amar U. Kishan and Percy Lee* \\ Department of Radiation Oncology, David Geffen School of Medicine, University of California, Los Angeles, USA
}

\begin{abstract}
When discussing local treatment modalities, physicians often quip that there can be no blind surgeons, suggesting that an inherent advantage to surgery is the ability to precisely visualize the target. Advances in radiation therapy (RT) technology over the years have significantly improved the radiation oncologists' abilities to precisely sculpt high-dose radiation to a variety of targets, simultaneously improving local control and toxicity profiles. However, even the most sophisticated methods of CT-based image-guided radiotherapy (IGRT) are hampered by limitations that can compromise target localization and motion management. Additionally, realtime adaptive radiotherapy (ART) programs, wherein radiation plans can be molded to fit the often malleable anatomy of tumors and organs-at-risk, have not yet been developed. For these reasons, MRI-guided RT is considered the next frontier of radiation oncology. However, the development of integrated MRI/RT-delivery platforms is complicated by several technical challenges that have precluded development of MRI-guided linear accelerators. By virtue of employing a low-field (0.35 T) MRI and three ${ }^{60}$ Co sources, a newly available tri- ${ }^{60}$ Co teletherapy system (MRIdian System ${ }^{\mathrm{TM}}$, ViewRay ${ }^{\mathrm{TM}}$, Cleveland, OH, USA) has tackled these technical concerns and has thus become the first MRI-guided RT platform with FDA approval for medical use. In this Review, we describe the abilities of this device to accomplish the goals of MRI-guided RT-improved target localization, sophisticated motion management, and on-line ART-by exploring published feasibility, proof-of-principle, and proof-of-practice studies.
\end{abstract}

\section{Introduction}

The paramount goal of radiation therapy (RT) is to achieve tumor control while sparing adjacent organs-at-risk (OARs) from developing adverse effects. Rapidly evolving technological advances have led to the emergence of intensity modulated radiotherapy (IMRT), in which the intensity of the radiation fluence across the target volume can be varied to render the high-dose region conformal to irregularly-shaped targets, thereby limiting dose to nearby tissues [1]. The ability to deliver highly conformal RT, in turn, has propagated multiple developments in radiation oncology. First, an inherent risk with delivering such highly conformal RT is the possibility of a "geographic miss", wherein, as a result of inter- on intra-fraction motion, the target volume partially moves out of the high dose region [2]. This necessitates the use of image-guidance, wherein some form of "on-board imaging" (a cone beam CT (CBCT), ultrasound, or magnetic resonance imaging (MRI) is employed to ensure the alignment of the high-dose region to the target-a process known as image-guided radiotherapy or IGRT [3]. Additionally, strategies must be employed to mitigate or compensate for changes in target size, location, and shape related to inter- and intra-fraction organ motion. For example, strategies to minimize motion related to respiration include abdominal compression $[4,5]$ and active breath hold [6], while other strategies, such as respiratory gating and free-breathing treatments that include the limits of tumor motion within the target-simply account for motion [7-10]. Finally, changes in tumor size and/or patient anatomy over the course of RT can lead to further alterations in dose deposition, suggesting a benefit to adapting the radiation plan over time to account for these changes (adaptive radiation therapy, or ART) [11-28] . However, adaptive replanning has yet to remain widely adopted due to its time-intensive nature $[14,17,23,29]$. Furthermore, certain anatomical challenges such as those presented by the stochastic positioning of the small and large bowels (which move in real-time), cannot be effectively addressed without real-time "on-line" ART.
Finally, the ability to deliver highly conformal RT has allowed the emergence of stereotactic body radiotherapy (SBRT; also known as stereotactic ablative radiotherapy or SABR), wherein large doses of radiation are delivered over a small number of fractions $(\leq 5)$ to enhance tumor control [30]. The radiobiological rationale for this increased efficacy is beyond the scope of this Review, but includes a direct increase in biologically effective dose [31], direct endothelial cell damage leading to tumor cell apoptosis [32], vascular damage ultimately leading to tumor hypoperfusion and death [33], and/or an immunogenic effect $[34,35]$. SBRT has quickly become a mainstream technique for treating various malignant lesions, including non-small lung cancer [36,37], hepatocellular carcinoma [38,39], pancreatic adenocarcinoma [40], prostate adenocarcinoma [41,42], and oligometastatic lesions in various organs (particularly the lung and liver) [43-45]. Clearly, safe and effective delivery of SBRT necessitates sophisticated IGRT.

MRI-guided RT has the potential to improve target localization, optimize motion management, and facilitate ART, all by virtue of improved soft-tissue resolution [46,47]. However, the presence of a magnetic field can complicate RT delivery in two important ways. First, for an MRI to be integrated with a linear accelerator (LINAC), extensive magnetic shielding of the LINAC components are needed to circumvent interference between the radiofrequency and magnetic fields [48]. Secondly, the MRI's magnetic field can cause alterations in planned dose delivery via the Lorentz force, which can both broaden the penumbra of a photon beam and cause an electron-return-effect;

Correspondence to: Percy Lee, Department of Radiation Oncology, David Geffen School of Medicine, University of California, Los Angeles, 200 Medical Plaza, Los Angles, CA 90095, USA, Tel:310- 825-9771, Fax: 310-794-9795; E-mail: percylee@mednet.ucla.edu

Key words: $M R I$, radiation therapy, cancer

Received: March 12 2016; Accepted: April 01, 2016; Published: April 06, 2016 
the magnitude of these effects is dependent on the strength of the magnetic field [49].

While integrated MRI-LINACs are currently under development, an alternative solution to the technical challenges posed by MRIbased RT has manifested in a commercially available platform that has gained FDA-approval for medical use. This teletherapy platform (tri- ${ }^{60}$ Co system; MRIdian System ${ }^{\mathrm{TM}}$, ViewRay ${ }^{\mathrm{TM}}$, Cleveland, OH, USA) incorporates three ${ }^{60} \mathrm{Co}$ sources mounted $120^{\circ}$ from each other on a rotating gantry (Figure 1) [46]. Since ${ }^{60} \mathrm{Co}$ undergoes radioactive decay naturally to emit gamma rays (therapeutic megavoltage photons), this tri- ${ }^{60} \mathrm{Co}$ system obviates the aforementioned MRI-LINAC interactions. Additionally, by using a 0.35 Tesla magnet, tri- ${ }^{60} \mathrm{Co}$ system minimizes the aforementioned Lorentz-force dependent effects on dose deposition.

The first patient to be treated with this system received radiation in February 2014, and only four institutions worldwide are currently treating patients using this platform (Washington University, St. Louis MO; University of Wisconsin, Madison WI; University of California at Los Angeles (UCLA), Los Angeles CA; Seoul National University, Seoul, Korea). Nonetheless, experience has accumulated rapidly a result of multiple proof-of-principle and feasibility studies, and many of the promised capabilities of this unit, and of MRI-guided RT in general, are being realized. In this focused Review, we will discuss the evidence for the advantages of MRI-guided RT utilizing this tri- ${ }^{60} \mathrm{Co}$ system in terms of target localization, motion management, and ART.

\section{A brief dosimetric comparison: $\mathrm{Tri}^{-{ }^{60} \mathrm{Co}-\text { based RT }}$ versus LINAC-based RT}

While ${ }^{60} \mathrm{Co}$-based RT platforms are still commonly used in the developing world, LINAC-based approaches have largely supplanted ${ }^{60} \mathrm{Co}$ platforms in the United States and Europe [50]. This is largely due to the superior dosimetric capabilities afforded by LINACs. ${ }^{60} \mathrm{Co}$-based devices due to its lower energy spectrum typically generate beams that have less penetration and broader penumbrae, creating an inferior dose distribution. When utilized in conjunction with modern technological advances involved in IMRT (e.g., multi-leaf collimators and inverse planning software), ${ }^{60} \mathrm{Co}$-based devices may be able to deliver

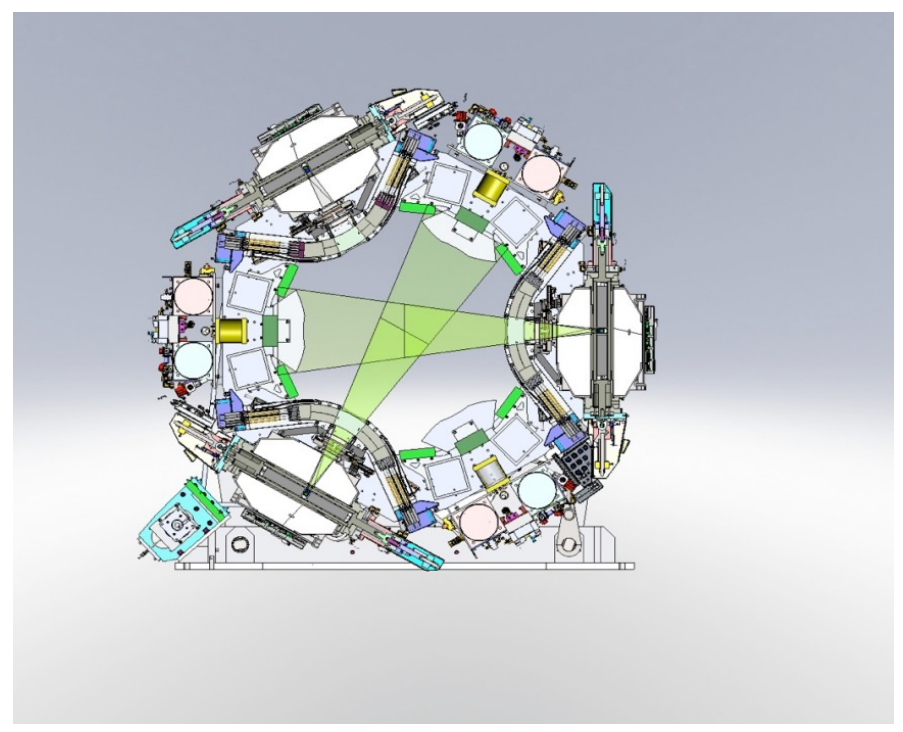

Figure 1. Schematic of the tri- ${ }^{60} \mathrm{Co}$ system.

The source configuration is shown, with two sources active. dosimetrically comparable plans. As mentioned, the tri- ${ }^{60} \mathrm{Co}$ system includes three ${ }^{60} \mathrm{Co}$ sources mounted $120^{\circ}$ from each other on a rotating gantry (Figure 1). The three sources rotate in concert, and therefore a beam group can be defined as a group of up to three ${ }^{60} \mathrm{Co}$-generated photon beams positioned at a particular gantry angle. Dosimetric feasibility studies have demonstrated that this tri- ${ }^{60} \mathrm{Co}$ geometric configuration in particular can allow delivery plans dosimetrically comparable to those deliver by a LINAC [51-55]. Investigators at the University of California, Los Angeles (UCLA) compared the dosimetry between LINAC-based and tri- ${ }^{60} \mathrm{Co}$ system-based SBRT plans for a variety of liver lesions in 16 patients, finding that tri- ${ }^{60} \mathrm{Co}$ systembased plans passed accepted national OAR dose constraint guidelines in all cases, though small, peripheral lesions appeared to be the best candidates for treatment with regards to sparing the right kidney and normal liver [54]. The same group also demonstrated that the tri- ${ }^{60} \mathrm{Co}$ system-based SBRT plans afforded clinically acceptable dosimetry in 18 of 20 patients with central lung lesions, with similar target conformality and OAR-sparing when compared with LINAC-based plans [55], and similarly reported equivalent dosimetry when comparing tri- ${ }^{60} \mathrm{Co}$ system-based and LINAC-based IMRT plans for soft tissue sarcomas of the extremity [53]. Finally, investigators at Washington University, St. Louis reported that the tri- ${ }^{60} \mathrm{Co}$ system could deliver dosimetrically comparable IMRT plans for 33 patients across a variety of disease sites ( 10 patients with targets in the abdomen, 14 in the pelvis, 6 in the thorax, and 3 in the head and neck) [52]. The investigators noted that OARs were better spared from low-dose (i.e., $<20 \mathrm{~Gy}$ ) spillage with LINAC-based plans, but comparable OAR dosimetry for doses $>20 \mathrm{~Gy}$. Notably, in all four of these comparative series, planning margins were not adjusted-an advantage offered by superior IGRT, such as with MRI-guidance, would be a reduction in doses to OARs subsequent to a smaller high dose volume.

Taken together, for the 78 radiation plans compared across these four studies, in 76 instances $(97.4 \%)$, the tri- ${ }^{60}$ Co system and LINACs produced clinically comparable plans. Notably, these dosimetric comparisons do not include consideration of low-dose contributions from on-board imaging involved in IGRT. While doses attributed to IGRT scans are low-averaging between 1.1 and $8.3 \mathrm{cGy}$ for a single CBCT - these low doses can still accumulate over a fractionated course of RT and thus be of theoretical concern with respect to the stochastic risk of secondary malignancy [56-59]. As it employs an on-board MRI, the tri $-{ }^{60} \mathrm{Co}$ system obviates any contribution of dose from the IGRT component of treatment.

\section{Target localization}

Precise target localization is a prerequisite for effective radiotherapy, as it minimizes the risk of a geographic miss and allows more precise sculpting of high-dose regions, thereby simultaneously allowing dose-escalation to the target and sparing of adjacent OARs. One strategy for target localization involves the implantation of fiducial markers into the target. For example, inter-fraction prostatic motion is difficult to precisely account for with conventional on-board imaging, and therefore three fiducial markers are often placed into the prostate to allow localization on orthogonal x-ray images or CBCT [60-62]. The CyberKnife system allows robotic tracking of implanted fiducial markers, wherein multiple pairs of two $45^{\circ}$ - angled radiographs are used to align the beam to the implanted fiducials $[63,64]$. While effective, implanting fiducials is an invasive procedure not without risks, such as pain bleeding, pneumothorax and fiducial migration $[65,66]$. The NovalisTx system employs a dual X-ray stereoscopic alignment system known as ExacTrac X-Ray 6D to allow alignment to externally placed 
infrared markers that function as surrogates of internal target motion $[67,68]$. Since external surface motion and internal motion may not completely correlate, subsequent imaging-such as CBCTs-may be needed. These CBCTs, in turn, have limited soft tissue resolution and may not be accurate for non-osseous targets and/or smaller lesions. MRI-guidance may thus allow for superior image-guidance, particularly for lesions in the central nervous system, thorax, head and neck, abdomen, pelvis, and soft tissues [69,70]. Comparative images of a patient with two liver lesions are shown in Figure 2, indicating the superiority of MRI in delineating soft tissue anatomy and highlighting target lesions.

However, for the aforementioned technical limitations, combining a high-field MRI with an RT delivery system is technically challenging. Since the tri- ${ }^{60} \mathrm{Co}$ system uses a low-field, $0.35 \mathrm{~T}$ MRI, a potential drawback is that the full benefits of MRI-guidance cannot be realized due to a low signal-to-noise ratio. Two recent studies have directly explored this potential limitation of the on-board low-field MRI. Noel et al. tasked three radiation oncologists with evaluating target and OAR visualization in 15 patients based on traditional CBCT (and megavoltage CT) images versus $0.35 \mathrm{~T}$ MRI images from the tri- ${ }^{60} \mathrm{Co}$ system [71]. The relevant fields of view included the thorax $(n=2)$, pelvis $(\mathrm{n}=6)$, abdomen $(\mathrm{n}=3)$, and head and neck $(\mathrm{n}=3)$. The MRI images were thought to be superior for $71 \%$ of structures and equivalent for $14 \%$. When restricted to target visualization, the MRI was thought to be superior in $40 \%$ of instances, while on-board CT imaging was never thought to be superior. Quantitative comparison of inter-observer agreement also showed superiority of the MRI images for targets and OARs. Of note, however, CT-based IGRT was thought to be superior in certain high-density structures, namely the ribs, vertebral bodies, and in some cases, cartilaginous structures such as the larynx.

Investigators at the University of Wisconsin have reported successful MRI-guided SBRT for hepatic lesions using gadoxetate contrast to effectively highlight the target despite limitations with low-field strength [72]. Five patients underwent diagnostic MRI scans and MRI-RT planning scans on the tri- ${ }^{60} \mathrm{Co}$ system using gadoxetate contrast, and then subsequently had gadoxetate injected 20 minutes prior to each treatment session. The investigators were able to confidently delineate the target and create a boundary region for the purposes of gating (discussed in further detail below, in section IV on Motion Management) without further internal or external surrogates to track motion.

It is important to underscore that the aforementioned studies all utilized a CT scan for radiation planning purposes, as current algorithms for dose computation are largely based off of electron

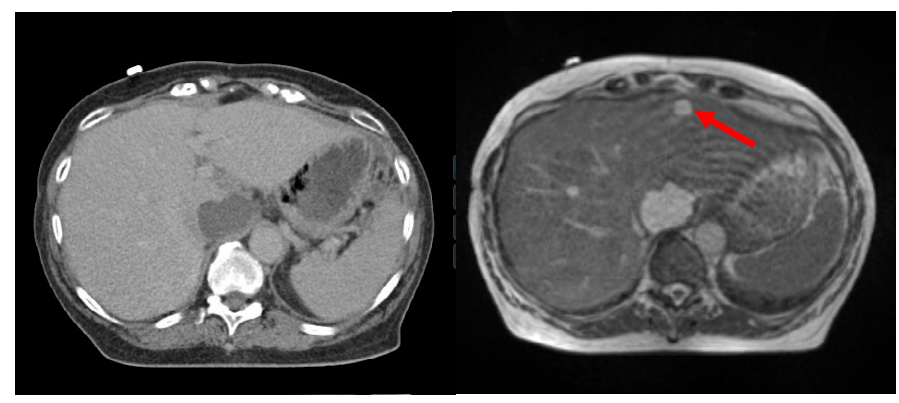

Figure 2.Comparison of target visualization based on CT (left) and MRI (right) for a patient with multiple liver lesions.

The smaller, anterior lesion is not visualized on CT (arrow points to the smaller tumor seen on the MRI (right). density information, which an MRI cannot provide. Interest in purely MRI-based treatment is high [70], but experience is relatively limited. A recent dosimetric study in a variety of disease sites suggested the maximum dosimetric error accrued from exclusive MRI-based planning is on the order of $1.6 \%$ [73], and efforts are underway at multiple institutions to transition towards exclusive MRI planning using bulk density estimations and assignments for bone, soft tissue, and air as a strategy.

\section{Motion management}

Even following precise target localization, tumor and OAR motion must be accounted for or mitigated. Of course, target localizationsuch as alignment to implanted fiducials-is intimately related to motion management, but that process alone is insufficient to account for intra-fraction motion, such as that caused by respiratory motion. Early approaches did include fluoroscopic visualization to quantify diaphragmatic excursion and/or align to implanted metallic fiducials markers [74]. Abdominal compression [4,5,75] and active breath hold $[6,76]$ are two means of minimizing motion associated with respiration, but may be associated with patient discomfort and are affected by patient compliance. The internal target volume (ITV) method strives to account for motion by creating an "envelope" around the tumor volume that encompasses motion of the tumor as visualized on a free-breathing scan $[9,10]$. The ITV approach is practical and easy to employ, but the generation of the ITV can become inaccurate in situations of large tumor motion, and larger volumes of adjacent tissues may receive radiation dose when treating the entire potential extent of tumor motion [77]. Respiratory gating [76,78,79] involves continuously monitoring the respiratory cycle and only treating when the target volume is within a predefined boundary region, constituting only a certain part of the respiratory cycle. Typically, this requires sophisticated imaging capabilities in order to monitor tumor motion and may in fact require fiducial markers, unless the on-board imaging capabilities are accurate enough to allow direct target visualization. Should such high-fidelity imaging be available, gating may be the most accurate and least invasive of the aforementioned motion management studies. It should also be noted that all such strategies use some form of modeling to predict internal tumor motion, which may introduce additional errors (as oppose to tracking and visualizing the tumor motion directly).

Paganelli et al. recently reported the feasibility of tracking liver motion using fast dynamic MRI imaging in 30 subjects [80]. The investigators used scale invariant feature transform (SIFT) to extract multiple spatially distributed features from MRI images, which they then tracked in cine-MRI series. Motion derived from this method was compared with motion obtained from tracking based on external surrogates. When compared with external or internal surrogate-based tracking, the investigators found that the gain afforded by utilizing MRI-guidance increases sharply based on the required tracking accuracy, with a gain of $>50 \%$ in 17 of the 30 subjects if the required error threshold was $1 \mathrm{~mm}$.

Mazur et al. further demonstrated the feasibility of using SIFTbased pixel tracking utilizing the $0.35 \mathrm{~T}$ cine-MRI images from the tri- ${ }^{60} \mathrm{Co}$ system [81]. Given the low signal-to-noise ratio with a $0.35 \mathrm{~T}$ MRI, the investigators generated SIFT descriptors to label and track pixels, and further utilized deformable spatial pyramid techniques to match pixels across frames in a cine-MRI. Utilizing this approach to retrospectively assess images obtained from 19 patients treated with the tri- ${ }^{60} \mathrm{Co}$ system, the mean tracking errors per patient were less than one 
pixel. Harmonic analyses of motion further improved the robustness of tracking, and a gating optimization method for use immediately prior to treatment was developed. Additionally, the aforementioned experience from University of Wisconsin utilizing gadoxetate for enhanced tumor localization for liver SBRT has also been advantageous when employed for gating [72] and tracking the tumor. Typically, tumors appear darker compared to their normal tissue counterpart when the patient is injected with intravenous gadoxetate. The investigators generated a boundary region based on a maximum-inspiratory breath-hold and restricted the "beam-on" time to the portions of treatment where $95 \%$ of the gross tumor volume was within this boundary region. Patients were provided with feedback by the radiation therapist during the treatment to optimize the amount of time the gross tumor volume was within this boundary.

Based on these data, gating-based approaches to treatment, at least for mobile targets that can be visualized with an on-board MRI, appear to be the most accurate means of managing motion. The on-board MRI, even with low-field strength, should provide accurate target localization, and either contrast-enhancement or image manipulation can be used to faithfully track the tumor despite a low signal-to-noise ratio. Currently, the tri- ${ }^{60} \mathrm{Co}$ system has the capacity to provide eight frames per second, and this capability is rapidly improving. Snapshots from the cine-MRI images employed for tracking a liver lesion are shown in Figure 3.

\section{Adaptive radiotherapy}

In addition to accounting for motion, radiation oncologists must also account for changes in tumor size and/or the patient's anatomy, which may require employing ART [11-13]. Dosimetric benefits to adaptive re-planning have been described primarily for treating

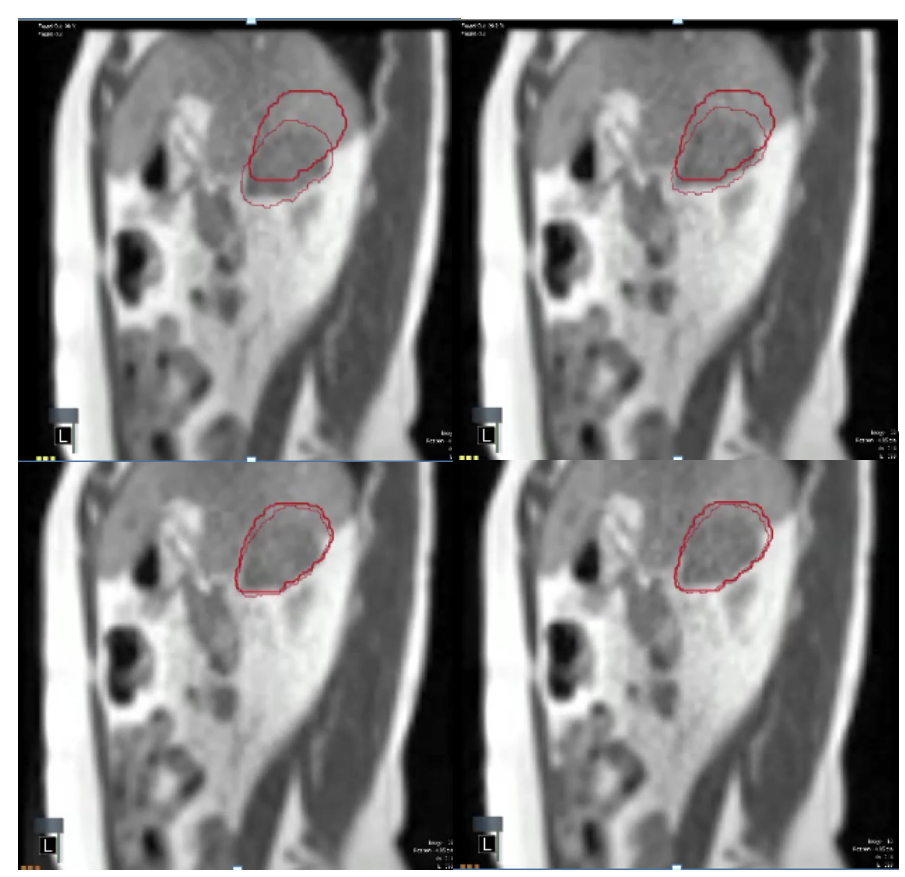

Figure 3. Real-time tumor tracking using the tri- ${ }^{60} \mathrm{Co}$ system.

Successive snapshots of a liver lesion as visualized using the real-time cine-MRI functionality of the tri- ${ }^{60} \mathrm{Co}$ system. The thick crimson outline indicates the "envelope" within which the radiation treatment will be delivered, while the softer crimson outline indicates the location of the tumor as it moves in real-time. The lesion is outside the "envelope" in the top row (radiation beam is off), and moves into the "envelope" in the bottom row (radiation beam is on). malignancies in the head and neck, in which both the tumor and the patient's anatomy may change (the latter due to weight loss) and for pelvic malignancies such as cervical cancer, in which the tumor is expected to regress significantly during $\mathrm{RT}$ and OAR displacement can be considerable [14-28]. However, adaptive re-planning has not been widely adopted due to both its time-intensive nature and limitations in the resolution of the on-board CT based imaging in order to be used for target and normal tissue segmentation [14,17,23,29]. Indeed, implementing an ART program can be laborious, as ART requires imaging to confirm changes in anatomy, real-time re-contouring and re-planning, assessment of the dosimetric benefits of the new versus the old plan, and quality assurance on the delivery of the new plan. Additionally, essentially all previously reported experience with ART involves off-line ART; for organs such as the small and large bowel, which have continuous and stochastic changes in position, off-line ART will not be sufficient, and a real-time solution is necessary.

A key advantage to an integrated MRI-RT unit is the potential to utilize the higher fidelity of the on-board images to allow more accurate online ART, potentially by automating the re-contouring process. Prior studies have demonstrated the feasibility and accuracy of rigid, non-rigid, and semi-automatic registration with the utilization of weekly MRI images [82]. Investigators at the Princess Margaret Hospital recently reported improved target coverage for 15 cervical cancer patients who underwent hybrid adaptation utilizing off-line replanning based on weekly MRIs [83]. An integrated quality assurance program is also required to allow for efficient ART [84].

The Washington University group has recently reported the successful implementation of online ART utilizing the tri- ${ }^{60} \mathrm{Co}$ system [85]. Their workflow involved: (a) pre-treatment MRI scan utilizing the $0.35 \mathrm{~T}$ MRI, (b) manual re-contouring of the target and OARs if needed, (c) analysis of dosimetry and re-planning if necessary, (d) integrated quality assurance of the new plan utilizing in-house, proprietary software, and (e) delivery of RT. Three of the five patients in their pilot cohort required re-planning; in two patients, this was done due to increased dose to the small bowel, while for the third it was done due to tumor progression. The group then extended this process to a total of 20 patients ( 170 fractions in all). Of these 170 fractions, 52 (30.6\%) involved re-planning, and 92 (54.1\%) involved delivery of a previously generated adaptive plan. The median time required for recontouring, re-planning, and quality assurance was 26 minutes, with only 1 case requiring more than 40 minutes. In no instances was the adaptive plan inferior to the original plan.

Another intriguing use of ART is the potential to tailor treatment volume and dose based on functional evidence of tumor response. Diffusion MRI sequences have been shown to predict response to RT $[86,87]$ earlier than gross tumor size changes or metabolic changes based on FDG PET-CT [88]. Both the baseline apparent diffusion coefficient (ADC) and changes in ADC, specifically increase in ADC after RT, correlate with tumor control and patient outcome after radiotherapy [89-94]. The UCLA group recently published the results of a pilot study utilizing a spin echo-based diffusion sequence on the tri- ${ }^{60} \mathrm{Co}$ system to track changes in diffusion over the course of RT for six patients [95]. This is the first study to use low-field MR to correlate ADC with clinical outcomes. The investigators first tested a 2D multislice spin echo single-shot echo planar imaging diffusion pulse sequence obtained data from these patients every two to five fractions. They noted that tumor ADC values changed throughout treatment, with intratumoral heterogeneity in large tumors. For one sarcoma patient with a $40 \%$ decrease in ADC between the fifth and eighth fraction (final), the post- 


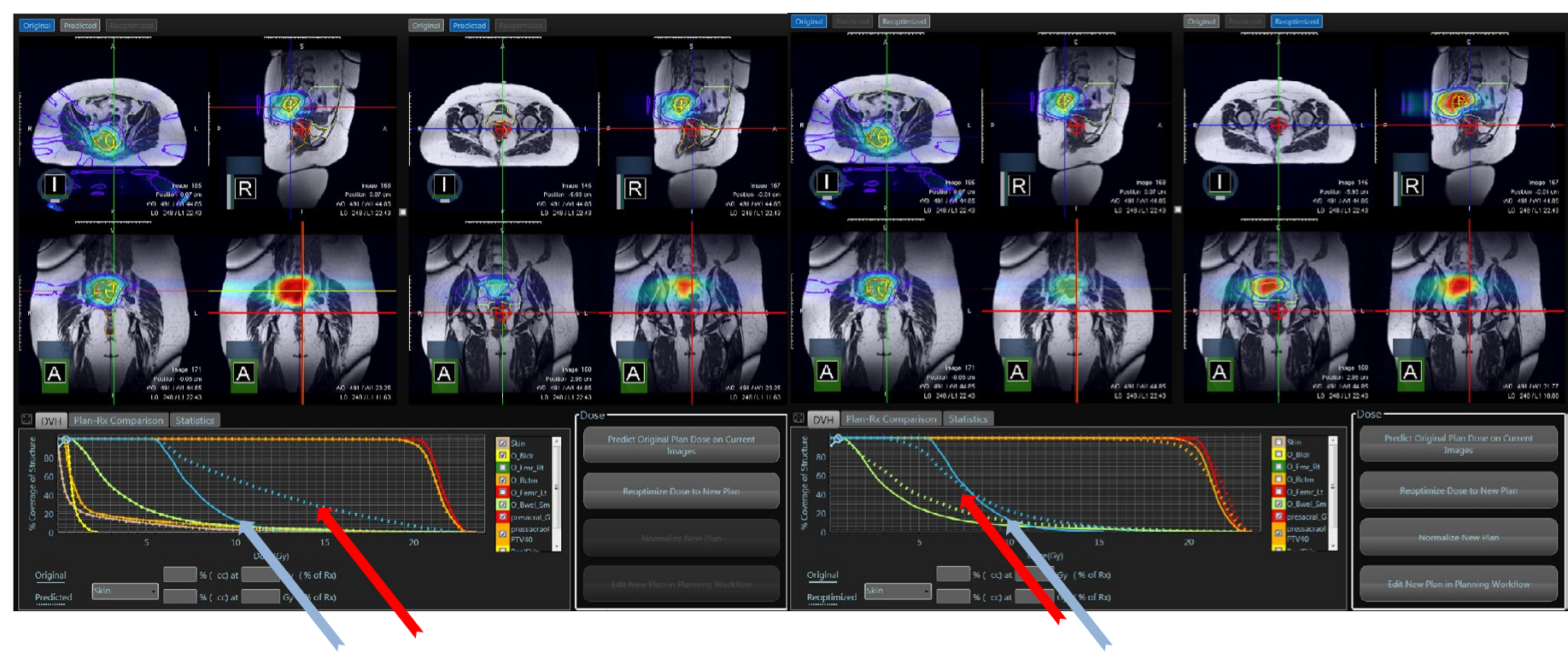

Figure 4. On-line adaptive replanning using the tri- ${ }^{60} \mathrm{Co}$ system.

(A) On-line re-contouring based off the anatomy visualized with the daily $0.35 \mathrm{~T}$ demonstrates doses to the small and large bowel that exceed what was originally intended (solid teal line/ solid blur arrow, planned; dotted teal line/solid red arrow, predicted). (B) After adaptive on-line re-planning, the predicted bowel dose is now re-optimized and comparable to what was originally planned, without compromising target coverage.

RT pathologic specimen showed a $<10 \%$ necrosis score, suggesting a clinical correlation between decrease in ADC and poor clinical outcome. Importantly, the ADC measurements found using the lowfield MRI were in agreement with previous experiences using $1.5 \mathrm{~T}$ or higher strength MRIs [94]. This may allow real-time ART based on real-time response in sub-volumes of tumor, allowing tailoring of dose based on real-time response.

Overall, these two clinical pilot studies suggest that the tri- ${ }^{60} \mathrm{Co}$ system can be used to expediently perform online-ART, and that in addition to providing anatomic information, the on-line low-field MRI may also be able to provide functional imaging information for tailoring RT. An example of a case in which changing anatomy would have led to increase dose to the bowel tissue without online ART is shown in Figure 4. Upon re-planning, the bowel dose returned to the optimal lower level as previously planned despite being in a different location then the anatomy seen on simulation. Target coverage to the tumor was maintained.

\section{Conclusion}

It has often been stated that there can never be a blind surgeon, as the surgeon must clearly see the target in order to faithfully remove it. Yet, for much of its history, radiation oncology has required its practitioners to be "blind" with respect to nuanced target anatomy. Only relatively recently have advances in radiation technology allowed for sophisticated IGRT, and even then, much of the image-guidance is based on CT imaging, which can be lacking in certain anatomic locations. An integrated MRI-guided RT system offers multiple technical advantages: improved target localization, accurate and noninvasive motion management, and the potential to adapt radiotherapy plans in real-time not just for anatomical changes, but for functional changes as well. The development of such MRI-guided RT systems is complicated by several physical conundrums related to the integration of a magnetic field with the RT delivery platform. The tri- ${ }^{60} \mathrm{Co}$ system circumvents many of these issues by utilizing a low-field MRI and ${ }^{60} \mathrm{Co}$-generated therapeutic radiation. Nonetheless, the proof-of- principle and feasibility studies reviewed above demonstrate that the tri- ${ }^{60} \mathrm{Co}$ system allows excellent tumor visualization, can faithfully track tumor motion, and can perform on-line ART. These are all advantages previous systems do not afford. While integrated MRI-LINACs are under development, the early successes of the tri- ${ }^{60} \mathrm{Co}$ system suggest that the era of MRI-guided RT is already underway. There should no longer be blind radiation oncologists in this new era.

\section{Conflict of interest disclosure}

PL has received speaking honorarium from ViewRay, Inc. related to discussing MRI-guided radiotherapy for cancer and its clinical implementation.

\section{References}

1. Webb S (2001) Intensity-Modulated Radiation Therapy (Series in Medical Physics and Biomedical Engineering) (1 $1^{\text {st }}$ edn). Series in Medical Physics and Biomedical Engineering. Boca Raton, FL: CRC Press.

2. Hong TS, Tomé WA, Chappell RJ, Chinnaiyan P, Mehta MP, et al. (2005) The impact of daily setup variations on head-and-neck intensity-modulated radiation therapy. Int $J$ Radiat Oncol Biol Phys 61: 779-788. [Crossref]

3. Jadon R, Pembroke CA, Hanna CL, Palaniappan N, Evans M, et al. (2014) A systematic review of organ motion and image-guided strategies in external beam radiotherapy for cervical cancer. Clin Oncol (R Coll Radiol) 26: 185-196. [Crossref]

4. Wunderink, W., et al., (2008) Reduction of respiratory liver tumor motion by abdominal compression in stereotactic body frame, analyzed by tracking fiducial markers implanted in liver. Int J Radiat Oncol Biol Phys 71: 907-15. [Crossref]

5. Eccles, C.L., et al., Comparison of liver tumor motion with and without abdominal compression using cine-magnetic resonance imaging. Int $J$ Radiat Oncol Biol Phys, 2011. 79: 602-8.

6. Dawson LA, Eccles C, Bissonnette JP, Brock KK (2005) Accuracy of daily image guidance for hypofractionated liver radiotherapy with active breathing control. Int $J$ Radiat Oncol Biol Phys 62: 1247-1252. [Crossref]

7. Shen Y, Zhang H, Wang J, Zhong R, Jiang X, et al. (2010) Hypofractionated radiotherapy for lung tumors with online cone beam $\mathrm{CT}$ guidance and active breathing control. Radiat Oncol 5: 19. [Crossref]

8. Jang SS, Huh GJ, Park SY, Yang PS, Cho EY (2014) The impact of respiratory gating 
on lung dosimetry in stereotactic body radiotherapy for lung cancer. Phys Med 30: 682-689. [Crossref]

9. Underberg RW, Lagerwaard FJ, Cuijpers JP, Slotman BJ, van Sörnsen de Koste JR, et al (2004) Four-dimensional CT scans for treatment planning in stereotactic radiotherapy for stage I lung cancer. Int J Radiat Oncol Biol Phys 60: 1283-1290. [Crossref]

10. Wang L, Hayes S, Paskalev K, Jin L, Buyyounouski MK, et al. (2009) Dosimetric comparison of stereotactic body radiotherapy using 4D CT and multiphase CT images for treatment planning of lung cancer: evaluation of the impact on daily dose coverage. Radiother Oncol 91: 314-324. [Crossref]

11. Jaffray DA (2012) Image-guided radiotherapy: from current concept to future perspectives. Nat Rev Clin Oncol 9: 688-699. [Crossref]

12. Yan D, Vicini F, Wong J, Martinez A (1997) Adaptive radiation therapy. Phys Med Biol 42: 123-132. [Crossref]

13. Yan D (2010) Adaptive radiotherapy: merging principle into clinical practice. Semin Radiat Oncol 20: 79-83. [Crossref]

14. Hansen EK, Bucci MK, Quivey JM, Weinberg V, Xia P (2006) Repeat CT imaging and replanning during the course of IMRT for head-and-neck cancer. Int J Radiat Oncol Biol Phys 64: 355-362. [Crossref]

15. O'Daniel JC, Garden AS, Schwartz DL, Wang H, Ang KK, et al. (2007) Parotid gland dose in intensity-modulated radiotherapy for head and neck cancer: is what you plan what you get? Int J Radiat Oncol Biol Phys 69: 1290-1296. [Crossref]

16. Wang W, Yang H, Hu W, Shan G, Ding W, et al. (2010) Clinical study of the necessity of replanning before the 25th fraction during the course of intensity-modulated radiotherapy for patients with nasopharyngeal carcinoma. Int J Radiat Oncol Biol Phys 77: 617-621. [Crossref]

17. Castadot P, Geets X, Lee JA, Christian N, Grégoire V (2010) Assessment by a deformable registration method of the volumetric and positional changes of target volumes and organs at risk in pharyngo-laryngeal tumors treated with concomitant chemo-radiation. Radiother Oncol 95: 209-217. [Crossref]

18. Lee C, Langen KM, Lu W, Haimerl J, Schnarr E, et al. (2008) Assessment of parotid gland dose changes during head and neck cancer radiotherapy using daily megavoltage computed tomography and deformable image registration. Int J Radiat Oncol Biol Phys 71: 1563-1571. [Crossref]

19. Wu Q, Chi Y, Chen PY, Krauss DJ, Yan D, et al. (2009) Adaptive replanning strategies accounting for shrinkage in head and neck IMRT. Int J Radiat Oncol Biol Phys 75: 924-932. [Crossref]

20. Bhide SA, Davies M, Burke K, McNair HA, Hansen V, et al. (2010) Weekly volume and dosimetric changes during chemoradiotherapy with intensity-modulated radiation therapy for head and neck cancer: a prospective observational study. Int J Radiat Oncol Biol Phys 76: 1360-1368. [Crossref]

21. Marzi S, Pinnarò P, D'Alessio D, Strigari L, Bruzzaniti V, et al. (2012) Anatomical and dose changes of gross tumour volume and parotid glands for head and neck cancer patients during intensity-modulated radiotherapy: effect on the probability of xerostomia incidence. Clin Oncol (R Coll Radiol) 24: e54-62. [Crossref]

22. Loo H, Fairfoul J, Chakrabarti A, Dean JC, Benson RJ, et al. (2011) Tumour shrinkage and contour change during radiotherapy increase the dose to organs at risk but not the target volumes for head and neck cancer patients treated on the TomoTherapy HiArt system. Clin Oncol (R Coll Radiol) 23: 40-47. [Crossref]

23. Chen AM, Daly ME, Cui J, Mathai M, Benedict S, et al. (2014) Clinical outcomes among patients with head and neck cancer treated by intensity-modulated radiotherapy with and without adaptive replanning. Head Neck 36: 1541-1546. [Crossref]

24. Schwartz DL, Garden AS, Shah SJ, Chronowski G, Sejpal S, et al. (2013) Adaptive radiotherapy for head and neck cancer--dosimetric results from a prospective clinical trial. Radiother Oncol 106: 80-84. [Crossref]

25. Castelli J, Simon A, et al. (2015) Impact of head and neck cancer adaptive radiotherapy to spare the parotid glands and decrease the risk of xerostomia. Radiat Oncol 10: 6 . [Crossref]

26. Ahn PH, Chen CC, Ahn AI, Hong L, Scripes PG, et al. (2011) Adaptive planning in intensity-modulated radiation therapy for head and neck cancers: single-institution experience and clinical implications. Int J Radiat Oncol Biol Phys 80: 677-85. [Crossref]

27. Liu F, Erickson B, Peng C, Li XA (2012) Characterization and management of interfractional anatomic changes for pancreatic cancer radiotherapy. Int J Radiat Oncol Biol Phys 83: e423-429. [Crossref]
28. Lim K, Stewart J, Kelly V, Xie J, Brock KK, et al. (2014) Dosimetrically triggered adaptive intensity modulated radiation therapy for cervical cancer. Int J Radiat Oncol Biol Phys 90: 147-154. [Crossref]

29. Schwartz DL, Garden AS, Thomas J, Chen Y, Zhang Y, et al. (2012) Adaptive radiotherapy for head-and-neck cancer: initial clinical outcomes from a prospective trial. Int J Radiat Oncol Biol Phys 83: 986-993. [Crossref]

30. Kollar L, Rengan R2 (2014) Stereotactic body radiotherapy. Semin Oncol 41: 776-789. [Crossref]

31. Hall EJ, Giaccia AJ (2011) Radiobiology for the Radiologist. ( $7^{\text {th }}$ edn). Philadelphia: Lippincott Williams \& Wilkins.

32. Garcia-Barros M, Paris F, Cordon-Cardo C, Lyden D, Rafii S, et al. (2003) Tumor response to radiotherapy regulated by endothelial cell apoptosis. Science 300: 11551159. [Crossref]

33. Park HJ, Griffin RJ, Hui S, Levitt SH, Song CW (2012) Radiation-induced vascular damage in tumors: implications of vascular damage in ablative hypofractionated radiotherapy (SBRT and SRS). Radiat Res 177: 311-327. [Crossref]

34. Gandhi SJ, Minn AJ, Vonderheide RH, Wherry EJ, Hahn SM, et al. (2015) Awakening the immune system with radiation: Optimal dose and fractionation. Cancer Lett 368 185-190. [Crossref]

35. Twyman-Saint Victor C, Rech AJ, Maity A, Rengan R, Pauken KE, et al. (2015) Radiation and dual checkpoint blockade activate non-redundant immune mechanisms in cancer. Nature 520: 373-377. [Crossref]

36. (2016) Network, N.C.C. Non-Small Cell Lung Cancer. (cited 2016 January 5); Available from: [http://www.nccn.org/professionals/physician_gls/pdf/nscl.pdf]

37. Shultz DB, Diehn M, Loo BW Jr (2015) To SABR or not to SABR? Indications and contraindications for stereotactic ablative radiotherapy in the treatment of early-stage, oligometastatic, or oligoprogressive non-small cell lung cancer. Semin Radiat Oncol 25: 78-86. [Crossref]

38. Tanguturi SK, Wo JY, Zhu AX, Dawson LA, Hong TS (2014) Radiation therapy for liver tumors: ready for inclusion in guidelines? Oncologist 19: 868-879. [Crossref]

39. Wang PM, Chung NN, Hsu WC, Chang FL, Jang CJ, et al. (2015) Stereotactic body radiation therapy in hepatocellular carcinoma: Optimal treatment strategies based on liver segmentation and functional hepatic reserve. Rep Pract Oncol Radiother 20: 417 424. [Crossref]

40. Trakul N, Koong AC, Chang DT (2014) Stereotactic body radiotherapy in the treatmen of pancreatic cancer. Semin Radiat Oncol 24: 140-147. [Crossref]

41. Meier R (2015) Dose-Escalated Robotic SBRT for Stage I-II Prostate Cancer. Front Oncol 5: 48. [Crossref]

42. (2015) Network, N.C.C. NCCN Clinical Practice Guidelines in Oncology: Prostate Cancer. 2015 11/10/2015 11/30/2015]; Version I.2016: Available from: [http://www. nccn.org/professionals/physician_gls/pdf/prostate.pdf].

43. Hanna GG, Landau D (2015) Stereotactic body radiotherapy for oligometastatic disease. Clin Oncol (R Coll Radiol) 27: 290-297. [Crossref]

44. Chang DT, Swaminath A, Kozak M, Weintraub J, Koong AC, et al. (2011) Stereotactic body radiotherapy for colorectal liver metastases: a pooled analysis. Cancer 117: 40604069. [Crossref]

45. Tree AC, Khoo VS, Eeles RA, Ahmed M, Dearnaley DP, et al. (2013) Stereotactic body radiotherapy for oligometastases. Lancet Oncol 14: e28-37. [Crossref]

46. Mutic S, Dempsey JF (2014) The ViewRay system: magnetic resonance-guided and controlled radiotherapy. Semin Radiat Oncol 24: 196-199. [Crossref]

47. Kupelian P, Sonke JJ (2014) Magnetic resonance-guided adaptive radiotherapy: a solution to the future. Semin Radiat Oncol 24: 227-232. [Crossref]

48. (2011) Adaptive Motion Compensation in Radiotherapy Imaging in Medical Diagnosis and Therapy. CRC Press.

49. Raaijmakers AJ, Raaymakers BW, Lagendijk JJ (2008) Magnetic-field-induced dose effects in MR-guided radiotherapy systems: dependence on the magnetic field strength. Phys Med Biol 53: 909-923. [Crossref]

50. Page BR, Hudson AD, Brown DW, Shulman AC, Abdel-Wahab M, et al. (2014) Cobalt, linac, or other: what is the best solution for radiation therapy in developing countries? Int J Radiat Oncol Biol Phys 89: 476-480. [Crossref]

51. Saenz DL, Paliwal BR, Bayouth JE (2014) A dose homogeneity and conformity 
evaluation between ViewRay and pinnacle-based linear accelerator IMRT treatment plans. J Med Phys 39: 64-70. [Crossref]

52. Wooten HO, Green O, Yang M, DeWees T, Kashani R, et al. (2015) Quality of Intensity Modulated Radiation Therapy Treatment Plans Using a (6)(0)Co Magnetic Resonance Image Guidance Radiation Therapy System. Int J Radiat Oncol Biol Phys 92: 771-778. [Crossref]

53. Kishan AU, Cao M, Mikaeilian AG, Low DA, Kupelian PA, et al. (2015) Dosimetric feasibility of magnetic resonance imaging-guided tri-cobalt 60 preoperative intensity modulated radiation therapy for soft tissue sarcomas of the extremity. Pract Radiat Oncol 5: 350-356. [Crossref]

54. Kishan AU, Cao M, Wang PC, Mikaeilian AG, Tenn S, et al. (2015) Feasibility of magnetic resonance imaging-guided liver stereotactic body radiation therapy: A comparison between modulated tri-cobalt-60 teletherapy and linear accelerator-based intensity modulated radiation therapy. Pract Radiat Oncol 5: 330-337. [Crossref]

55. Merna C, Rwigema JC, Cao M, Wang PC, Kishan AU, et al. (2016) A treatment planning comparison between modulated tri-cobalt-60 teletherapy and linear accelerator-based stereotactic body radiotherapy for central early-stage non-small cell lung cancer. Med Dosim 41: 87-91. [Crossref]

56. Hall EJ, Wuu CS (2003) Radiation-induced second cancers: the impact of 3D-CRT and IMRT. Int J Radiat Oncol Biol Phys 56: 83-88. [Crossref]

57. Islam MK, Purdie TG, Norrlinger BD, Alasti H, Moseley DJ, et al. (2006) Patient dose from kilovoltage cone beam computed tomography imaging in radiation therapy. Med Phys 33: 1573-1582. [Crossref]

58. Kim S, Yoshizumi TT, Frush DP, Toncheva G, Yin FF (2010) Radiation dose from cone beam CT in a pediatric phantom: risk estimation of cancer incidence. AJR Am J Roentgenol 194: 186-190. [Crossref]

59. Song WY, Kamath S, Ozawa S, Ani SA, Chvetsov A, et al. (2008) A dose comparison study between XVI and OBI CBCT systems. Med Phys 35: 480-486. [Crossref]

60. Pouliot J, Aubin M, Langen KM, Liu YM, Pickett B, et al. (2003) (Non)-migration of radiopaque markers used for on-line localization of the prostate with an electronic portal imaging device. Int J Radiat Oncol Biol Phys 56: 862-866. [Crossref]

61. Balter JM, Lam KL, Sandler HM, Littles JF, Bree RL, et al. (1995) Automated localization of the prostate at the time of treatment using implanted radiopaque markers: technical feasibility. Int J Radiat Oncol Biol Phys 33: 1281-1286. [Crossref]

62. Shirato H, Harada T, Harabayashi T, Hida K, Endo H, et al. (2003) Feasibility of insertion/implantation of 2.0-mm-diameter gold internal fiducial markers for precise setup and real-time tumor tracking in radiotherapy. Int J Radiat Oncol Biol Phys 56: 240-247. [Crossref]

63. Casamassima F, Cavedon C, Francescon P, Stancanello J, Avanzo M, et al. (2006) Use of motion tracking in stereotactic body radiotherapy: Evaluation of uncertainty in offtarget dose distribution and optimization strategies. Acta Oncol 45: 943-947. [Crossref]

64. Mallarajapatna GJ, Susheela SP, Kallur KG, Ramanna NK, Ramachandra PG, et al. (2011) Technical note: Image guided internal fiducial placement for stereotactic radiosurgery (CyberKnife). Indian J Radiol Imaging 21: 3-5. [Crossref]

65. Yousefi S, Collins BT, Reichner CA, Anderson ED, Jamis-Dow C, et al. (2007) Complications of thoracic computed tomography-guided fiducial placement for the purpose of stereotactic body radiation therapy. Clin Lung Cancer 8: 252-256. [Crossref]

66. Roberge D, Cabrera T (2011) Percutaneous Liver Fiducial Implants: Techniques, Materials, and Complications. In: Liver Biopsy in Modern Medicine. Mizuguchi Y, Editor. InTech.

67. Jin JY, Yin FF, Tenn SE, Medin PM, Solberg TD (2008) Use of the BrainLAB ExacTrac X-Ray 6D system in image-guided radiotherapy. Med Dosim 33: 124-134. [Crossref]

68. Verellen D, Soete G, Linthout N, Van Acker S, De Roover P, et al. (2003) Quality assurance of a system for improved target localization and patient set-up that combines real-time infrared tracking and stereoscopic X-ray imaging. Radiother Oncol 67: 129141. [Crossref]

69. Khoo VS, Dearnaley DP, Finnigan DJ, Padhani A, Tanner SF, et al. (1997) Magnetic resonance imaging (MRI): considerations and applications in radiotherapy treatment planning. Radiother Oncol 42: 1-15. [Crossref]

70. Devic S (2012) MRI simulation for radiotherapy treatment planning. Med Phys 39: 6701-6711. [Crossref]

71. Noel CE, Parikh PJ, Spencer CR, Green OL, Hu Y, et al. (2015) Comparison of onboard low-field magnetic resonance imaging versus onboard computed tomography for anatomy visualization in radiotherapy. Acta Oncol 54: 1474-1482. [Crossref]
72. Wojcieszynski AP, Rosenberg SA, Brower JV, Hullett CR, Geurts MW, et al. (2016) Gadoxetate for direct tumor therapy and tracking with real-time MRI-guided stereotactic body radiation therapy of the liver. Radiother Oncol 118: 416-418. [Crossref]

73. Jonsson JH, Karlsson MG, Karlsson M, Nyholm T (2010) Treatment planning using MRI data: an analysis of the dose calculation accuracy for different treatment regions. Radiat Oncol 5: 62. [Crossref]

74. Kothary N, Heit JJ, Louie JD, Kuo WT, Loo BW Jr, et al. (2009) Safety and efficacy of percutaneous fiducial marker implantation for image-guided radiation therapy. $J$ Vasc Interv Radiol 20: 235-239. [Crossref]

75. Yorke E, Xiong Y, Han Q, Zhang P, Mageras G, et al. (2015) Kilovoltage Imaging of Implanted Fiducials to Monitor Intrafraction Motion With Abdominal Compression During Stereotactic Body Radiation Therapy for Gastrointestinal Tumors. Int J Radiat Oncol Biol Phys. [Crossref]

76. Bloemen-van Gurp E, van der Meer S, Hendry J, Buijsen J, Visser P, et al. (2013) Active breathing control in combination with ultrasound imaging: a feasibility study of image guidance in stereotactic body radiation therapy of liver lesions. Int $J$ Radiat Oncol Biol Phys 85: 1096-1102. [Crossref]

77. Peng J, Zhang Z, Wang J, et al. (2016) Is internal target volume accurate for dose evaluation in lung cancer stereotactic body radiotherapy? Oncotarget. [Crossref]

78. Wagman R, Yorke E, Ford E, Giraud P, Mageras G, et al. (2003) Respiratory gating for liver tumors: use in dose escalation. Int J Radiat Oncol Biol Phys 55: 659-668 [Crossref]

79. Briere TM, Beddar S, Balter P, Murthy R, Gupta S, et al. (2009) Respiratory gating with EPID-based verification: the MDACC experience. Phys Med Biol 54: 3379-3391. [Crossref]

80. Paganelli C, Seregni M, Fattori G, Summers P, Bellomi M, et al. (2015) Magnetic resonance imaging-guided versus surrogate-based motion tracking in liver radiation therapy: a prospective comparative study. Int J Radiat Oncol Biol Phys 91: 840-848. [Crossref]

81. Mazur TR, Fischer-Valuck BW, Wang Y, Yang D, Mutic S, et al. (2016) SIFT-based dense pixel tracking on $0.35 \mathrm{~T}$ cine-MR images acquired during image-guided radiation therapy with application to gating optimization. Med Phys 43: 279. [Crossref]

82. van der Put RW, Kerkhof EM, Raaymakers BW, Jürgenliemk-Schulz IM, Lagendijk JJ (2009) Contour propagation in MRI-guided radiotherapy treatment of cervical cancer: the accuracy of rigid, non-rigid and semi-automatic registrations. Phys Med Biol 54: 7135-7150. [Crossref]

83. Oh S, Stewart J, Moseley J, Kelly V, Lim K, et al. (2014) Hybrid adaptive radiotherapy with on-line MRI in cervix cancer IMRT. Radiother Oncol 110: 323-328. [Crossref]

84. Noel CE, Santanam L, Parikh PJ, Mutic S (2014) Process-based quality management for clinical implementation of adaptive radiotherapy. Med Phys 41: 081717. [Crossref]

85. Acharya S, Fischer-Valuck BW, Kashani R, Parikh P, Yang D, et al. (2016) Online Magnetic Resonance Image Guided Adaptive Radiation Therapy: First Clinical Applications. Int J Radiat Oncol Biol Phys 94: 394-403. [Crossref]

86. Bhatnagar P, Subesinghe M, Patel C, Prestwich R, Scarsbrook AF (2013) Functional imaging for radiation treatment planning, response assessment, and adaptive therapy in head and neck cancer. Radiographics 33: 1909-1929. [Crossref]

87. Tsien C, Cao Y, Chenevert T (2014) Clinical applications for diffusion magnetic resonance imaging in radiotherapy. Semin Radiat Oncol 24: 218-226. [Crossref]

88. Malayeri AA, El Khouli RH, Zaheer A, Jacobs MA, Corona-Villalobos CP, et al. (2011) Principles and applications of diffusion-weighted imaging in cancer detection, staging, and treatment follow-up. Radiographics 31: 1773-1791. [Crossref]

89. Decker G, Mürtz P, Gieseke J, Träber F, Block W, et al. (2014) Intensity-modulated radiotherapy of the prostate: dynamic ADC monitoring by DWI at 3.0 T. Radiother Oncol 113: 115-120. [Crossref]

90. Kuang F, Yan Z, Wang J, Rao Z (2014) The value of diffusion-weighted MRI to evaluate the response to radiochemotherapy for cervical cancer. Magn Reson Imaging 32: 342-349. [Crossref]

91. Kim S, Loevner L, Quon H, Sherman E, Weinstein G, et al. (2009) Diffusionweighted magnetic resonance imaging for predicting and detecting early response to chemoradiation therapy of squamous cell carcinomas of the head and neck. Clin Cancer Res 15: 986-994. [Crossref]

92. Yu JI, Park HC, Lim do H, Choi Y, Jung SH, et al. (2014) The role of diffusion-weighted magnetic resonance imaging in the treatment response evaluation of hepatocellular 
carcinoma patients treated with radiation therapy. Int J Radiat Oncol Biol Phys 89: 814-821. [Crossref]

93. Liu L, Wu N, Ouyang H, Dai JR, Wang WH (2014) Diffusion-weighted MRI in early assessment of tumour response to radiotherapy in high-risk prostate cancer. Br J Radiol 87: 20140359. [Crossref]
94. King AD, Chow KK, Yu KH, Mo FK, Yeung DK, et al. (2013) Head and neck squamous cell carcinoma: diagnostic performance of diffusion-weighted MR imaging for the prediction of treatment response. Radiology 266: 531-538. [Crossref]

95. Yang Y, Cao M, Sheng K, Gao Y, Chen A, et al. (2016) Longitudinal diffusion MRI for treatment response assessment: Preliminary experience using an MRI-guided tri-cobalt 60 radiotherapy system. Med Phys 43: 1369. [Crossref]

Copyright: $\odot 2016$ Kishan AU. This is an open-access article distributed under the terms of the Creative Commons Attribution License, which permits unrestricted use, distribution, and reproduction in any medium, provided the original author and source are credited. 